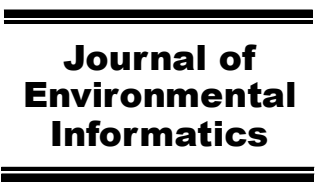

Www.iseis.org/jei

\title{
Variability in MODIS NDVI in Relation to Southwest Monsoon over Western Ghats, India
}

\author{
T. V. Lakshmi Kumar ${ }^{1,}{ }^{*}$, R. Uma ${ }^{1}$, K. Koteswara Rao ${ }^{2}$, H. Barbosa ${ }^{3}$, E. Prabha Jothi ${ }^{4}$, and K. V. K. R. K. Patnaik ${ }^{5}$ \\ ${ }^{1}$ Atmospheric Science Research Laboratory, Department of Physics, SRM University, Kattankulathur 603203, India \\ ${ }^{2}$ Climatology \& Hydrometeorology Division, Indian Institute of Tropical Meteorology, Pune 411008, India \\ ${ }^{3}$ Universidade Federal de Alagoas, UFAL, Maceió, AL, 57072-970, Brasil \\ ${ }^{4}$ Karnataka State Natural Disaster Monitoring Centre, Bangalore 560064, India \\ Indian Maritime University, Visakhapatnam 530005, India
}

Received April 9, 2014; revised January 7, 2015; accepted January 26, 2015; published online November 16, 2015

\begin{abstract}
Eleven years (2000 to 2010) of Normalized Difference Vegetation Index (NDVI) data, derived from Moderate Imaging Spectroradiometer (MODIS) Terra with $250 \mathrm{~m}$ resolution is used in the present study to discuss the changes in the vegetal cover over Western Ghats, India. The NDVI over Western Ghats (number of test sites are 16) showed increasing tendency and the pronounced changes in NDVI have been studied in the context of southwest monsoon's distribution and activity. The NDVI progression is observed from June with a minimum value of 0.179 and yielded to a maximum at 0.565 during September/October, on an average. The study then relates NDVI with different rainy events to understand the connection between the ground vegetation and the south west monsoon. The results of the study inferred are as follows: i) NDVI, Antecedent Precipitation Index (API) are in good agreement throughout the monsoon which is evidenced by correlation; ii) NDVI maintained good correlation with a number of Light and Moderate Rainy days alternatively but not with the number of Heavy Rainy days; iii) Relation of NDVI with Isolated, Scattered distributions and active monsoons is substantial; and iv) Rate of Green Up is captured by the satellite during the crop growing season over the Western Ghats.
\end{abstract}

Keywords: MODIS NDVI, southwest monsoon, crop phenology, Western Ghats

\section{Introduction}

Southwest (SW) monsoon is considered to be the principal rainy season in India and its role in the country's economy is significant. The crops that grow in this season mainly use rain water from the monsoon to produce better yields. Thus, SW monsoon (June to September) has an impact on the productivity of the crop. Several studies carried out in studying the crops/agriculture in relation to meteorological parameters such as rainfall, temperature etc (Unganai \& Kogan, 1998; Kumar and Barbosa, 2012) and their influence is explained from literature. National Oceanic and Atmospheric Administration (NOAA) Advanced Very High Resolution Radiometer, MODIS Terra, SPOT VGT are a few satellite sensors providing vegetation indices to study the vegetation at fine resolution levels. NOAA AVHRR vegetation index, known as Normalized Difference Vegetation Index (NDVI) has been widely used to relate the synoptic meteorology/ cli-

\footnotetext{
${ }^{*}$ Corresponding author. Tel: +91 9962908939.

E-mail address: 1kumarap@hotmail.com (T. V. Lakshmi Kumar).
}

ISSN: $1726-2135$ print/1684-8799 online

(C) 2016 ISEIS All rights reserved. doi:10.3808/jei.201500320 matology to understand the vegetation dynamics, vegetation response to climate and climate vegetation feedback mechanism (Cihlar et al., 1991, Davenport and Nicholson, 1993, Barbosa and Kumar, 2011, Kumar et al., 2013). The studies of Kogan (1997), Unganai and Kogan (1998), and Ramesh et al. (2003) concluded that AVHRR NDVI is one of the best tools to monitor/assess the large area agricultural droughts.

Wan et al. (2004), Knight et al. (2006) and Funk et al. (2009) used NDVI derived from MODIS to understand the crop stages and long term disasters at finer resolution level. MODIS TERRA provide NDVI at $250 \mathrm{~m}$ resolution level from which one can make studies from a particular location point where ever required. Chang et al. (2011) studied the onset, offset and length of the growing period along with the inter-annual patterns of NDVI over Taiwan. In their study, they found that precipitation and temperature influence vegetation in distinct ways based on the type of the vegetation. Narasimhan and Stow (2010) studied the early season dynamics using MODIS NDVI across Alaska to understand the greening patterns of Arctic vegetation. Schnur et al. (2010) estimated the root zone soil moisture at distant sites using MODIS NDVI \& Enhanced Vegetation Index in a semi-arid region of SWern USA and found the growth correlation between NDVI and soil moisture. 

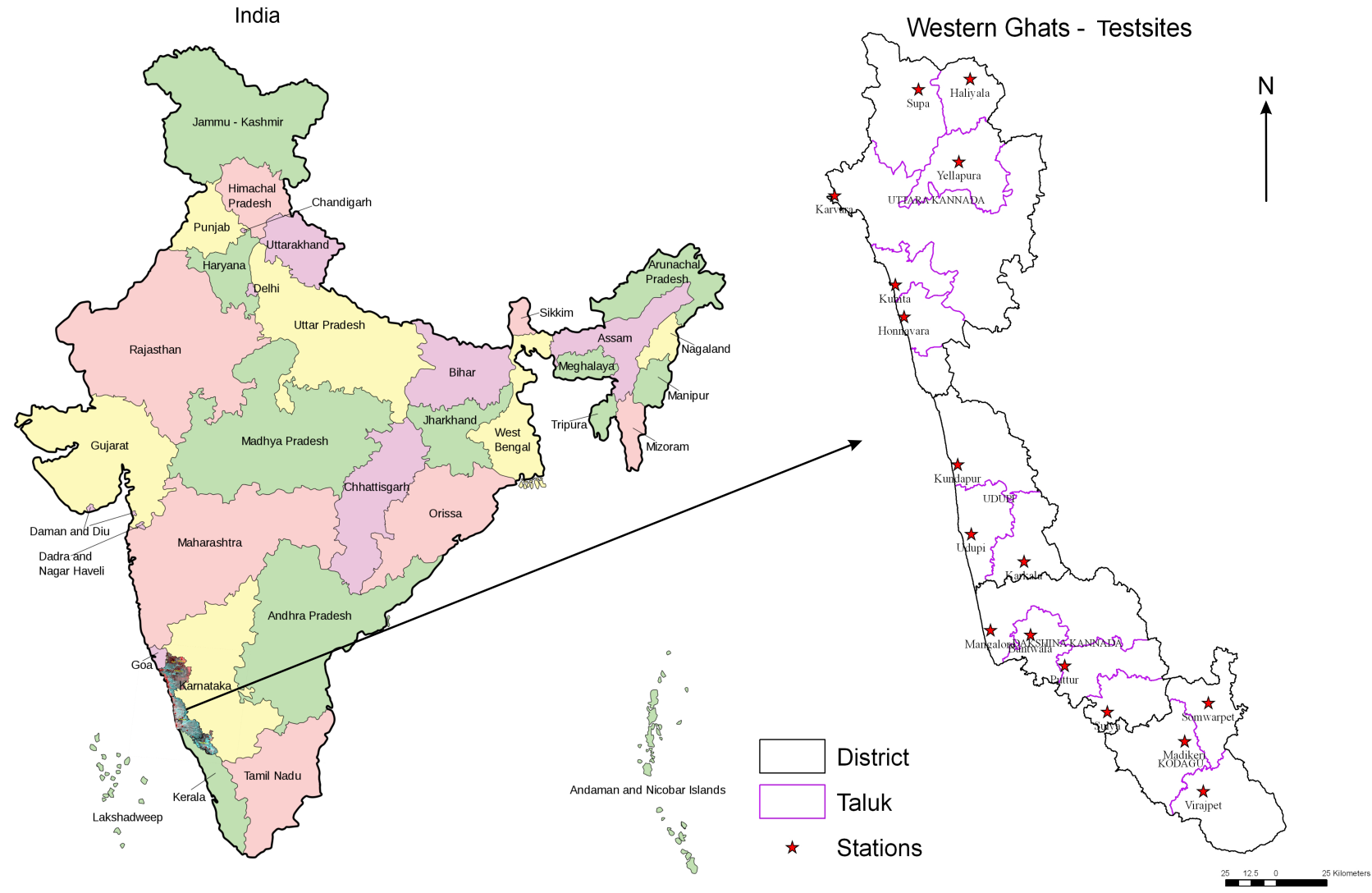

Figure 1. Location of the study area.

In the study of spatial patterns of NDVI over India, Lakshmi Kumar et al. (2013) reported that the NDVI is high in Western Ghats when compared to all other regions during southwest monsoon period. Using the principal component analysis, Lee et al. (2008) studied the relationship between NDVI and rainfall over India and reported that NDVI is dependant on SW monsoon over Western Ghats. It is also reported that due to climate change, the Western Ghats is going to receive exceptional amounts of rainfall during south west monsoon season which brings high contrast in the plant richness and diversity. Prasad et al. (2008) studied the effects of precipitation, temperature and topographic parameters on evergreen vegetation greenery in the Western Ghats, India and reported that the vegetion in Western Ghats is strongly dependant on seasonal rainfall. However, a few reports only available on the relationship of NDVI and rainfall and other climatic indices. Due to high topographic variability and heterogeneous land cover, Western Ghats attained the prominence in the country, India (Nagendra and Utkarsh, 2003). Also, the climate of the westrn ghats is humid as per the Thoronthwaite Climatic Approach (i.e moisture is above 80\%) and this makes the vegetation behavior different than in the arid regions, where the vegetation is directly dependent on rainfall.

In light of above, the present investigation is an attempt to study the MODIS NDVI variations over Western Ghats, located along the west coast of India. The time series analysis of NDVI during SW monsoon is of priority to understand the vegetation growth for the past 11 years from 2000 over the study region. Also, attempts were made to see these variations in relation to the number of light, moderate and heavy rainy days. The study also focuses in quantifying the relations of NDVI with monsoon distribution (isolated, scattered, fairly wide spread, wide spread) and monsoon activity (weak, normal, active, vigorous).

\section{Materials and Methods}

\subsection{Study Area}

The present study is focussed on Western Ghats which is located in peninsular region of India. The Western Ghats extends along the west coast of India from the latitude of $8.2^{\circ} \mathrm{N}$ to $15.6^{\circ} \mathrm{N}$ with an area of $160,000 \mathrm{sq} \mathrm{km}$. Western Ghats attained climatologically significance in India which is considered to be all time humid region (Sarma, 2006). The mean annual rainfall and temperatures are around $2,400 \mathrm{~mm}$ and 20 $22^{\circ} \mathrm{C}$ respectively. The SW monsoon (June to September) contributes nearly $80 \%$ of the annual rainfall. Rice and ragi are the major crops that grow during the SW monsoon season. The study area of investigation is given in Figure 1. 


\subsection{Methods}

MODIS surface reflectance 8 -day at $250 \mathrm{~m}$ resolution data (MOD09Q1.005) are available on the website of NASA Land Processes Distributed Active Archive Center (LP DAAC) (lpdaac.usgs.gov) supplied by National Aeronautics and Space Administration (NASA). The time interval of these pictures is eight days and accessible for peninsular region of India. These images are for free of cost, pre calibrated and cleaned for cloud effects using the maximum NDVI method (Holben, 1986; King et al., 2003). These products were downloaded and processed for SW monsoon season for 11 years i.e from 2000 to 2010 and NDVI values for the sixteen test sites were obtained. Actually, we derived NDVI values for more than 45 test stations in Western Ghats and selected only 16 for the present study which are relatively having minimum cloud effects during the south west monsoon season. ERDAS Imagine 2011 is used for the image analysis and the procedure for deriving NDVI is as follows. MODIS Data Downloading $\rightarrow$ Geometric Correction $\rightarrow$ Resampling $\rightarrow$ Cloud masking $\rightarrow$ NDVI Map generation $\rightarrow$ Statistical extraction $\rightarrow$ Nonagricultural area masking $\rightarrow$ NDVI Value calculation.

The NDVI is basically calculated from the visible and near-infrared light reflected by vegetation. Healthy vegetation (left) absorbs most of the visible light that hits it, and reflects a large portion of the near-infrared light. Unhealthy or sparse vegetation (right) reflects more visible light $(645 \mathrm{~nm})$ and less near-infrared $(857 \mathrm{~nm})$ light ( $\mathrm{Gu}$ et al., 2007). Using this concept, NDVI can be defined as the ratio of difference of near infrared and red to its sum. NDVI value varies from minus one $(-1)$ to plus one $(+1)$. The general classification of NDVI from Food and Agricultural Organization (FAO) is given below.

$$
\begin{aligned}
& \text { NDVI }<0 \quad-- \text { Water bodies } \\
& 0<\text { NDVI }<0.2 \text {-- Less Vegetation } \\
& 0.2<\text { NDVI }<0.4 \text {-- Medium Vegetation } \\
& \text { NDVI }>0.4 \text {-- High Vegetation }
\end{aligned}
$$

Daily rainfall data from ground rain gauges for the test sites were collected from Karnataka State Natural Disaster Monitoring Centre (KSNDMC), Bangalore, Karnataka, India for the period from 2000 to 2010 .

The authors have made an attempt to understand the relation between NDVI and rainfall. For this purpose using daily rainfall, Antecedent Precipitation Index (API) for the test sites has been calculated. The formulation of API given below was suggested by Rosenthal et al. (1982):

$A P I(j)=A P I(j-1) \times C+P_{t}$

where:

$j=$ current day;

$(j-1)=$ previous day;
$C^{t}=\left(P_{t} / P_{o}\right)$

where:

$P_{t}=t$ th day rainfall;

$P_{o}=$ starting day rainfall;

$A P I(0)=$ Initial day $A P I$

Pearson correlation is used to relate NDVI with API over the test sites of this study. Morlet wavelet analysis has been applied to NDVI and API to examine the periodicities among them. This analysis helps in identifying the corresponding changes that are associated with rainfall and vegetation.

The Morlet wavelet transform is a time-frequency representation, or more correctly time-scale, which breaks down a sign in components that appear in different scales or resolutions. This decomposition is performed through the expansion, contraction and displacement of a single function called wavelet. When this function is dilated, analyses of low frequency components, and when it is contracted, analyses of high frequency components. The continuous Wavelet tranform of a set of data $f(t) \varepsilon L^{2}(\mathbb{R})$ (Mallat, 1998) is defined as:

$C W T(u, \lambda)=\int_{-\infty}^{+\infty} f(t) \frac{1}{|\lambda|^{0.5}} \psi *\left(\frac{t-u}{\lambda}\right) d t$

where $*$ denotes the complex conjugate, $s$ is the parameter scale. The $C W T$ is a convolution of the data of rescaling of the Wavelet. In the equation, the space coordinate is equivalent to the coordinate time $t$. This study uses the Wavelet Morlet, which is defined as:

$\psi(t)=\frac{1}{\pi f_{b}} e^{2 \pi i f e^{x}} e^{-x^{2} / f_{b}}$

where it controls the bandwidth of the Wavelet and is the frequency of the Wavelet Morlet complex. A value of 1.0 was used in the order in which the scale is equivalent to the wavelength. The Wavelet in which the analysis is based may be chosen by their mathematical properties private. When the Wavelet is complex its real and imaginary part of a Hilbert transforms, ensures the orthogonality. The use of complex Wavelet has resulted in a complex $C W T$, and besides having a phase each time (or position) and scale.

Based on the amount of rainfall, categorization suggested by India Meteorological Department (IMD) is followed to distinguish the rainy days. Based on the number of sites recording rainfall and long term normal, IMD also suggested one criterion to explain the monsoon distribution and monsoon activity during the SW monsoon season over India.

\subsection{IMD Criterions}

\subsubsection{Categorization of Rainy Days}

Light Rainy Day (LR) - Rainfall from 2.5 to $7.4 \mathrm{~mm}$ (in- 
cluding Very Light Rain)

Moderate Rainy Day (MR) - Rainfall from 7.5 to 34.4 $\mathrm{mm}$

Heavy Rainy Day (HR) - Rainfall above $34.5 \mathrm{~mm}$ (including Rather Heavy Rains also)

\subsubsection{Monsoon Distribution}

Isolated (I) - Number (No.) of sites recording rainfall of $2.5 \mathrm{~mm}$ and above should be less than $25 \%$ of total number of sites.

Scattered (S) - Number of sites recording rainfall of 2.5 $\mathrm{mm}$ and above should be $25 \%$ to $50 \%$ of total number of sites.

Fairly Wide Spread (FWS) - Number of sites recording rainfall of $2.5 \mathrm{~mm}$ and above should be $50 \%$ to $75 \%$ of total number of sites.

Wide Spread (WS) - Number of sites recording rainfall of $2.5 \mathrm{~mm}$ and above should be above $75 \%$ of total number of sites.

\subsubsection{Monsoon Activity}

Weak $\left(\mathrm{M}_{\mathrm{w}}\right)$ - Actual rainfall should be below half of the normal

Normal $\left(\mathrm{M}_{\mathrm{N}}\right)$ - Actual rainfall should be in between half and one and half of the normal

Active $\left(\mathrm{M}_{\mathrm{A}}\right)$ - Actual rainfall should be one and half to four times of the normal. At least two places should get rain above $30 \mathrm{~mm}$ rainfall and rainfall distribution should be Fairly Wide Spread.

Vigorous $\left(\mathrm{MV}_{\mathrm{V}}\right)$ - Actual rainfall should be above four times to the normal and at least two places should get rainfall above $50 \mathrm{~mm}$ along with Fairly Wide Spread to Wide Spread rainfall distribution.

\section{Results and Discussion}

\subsection{Interannual Variability of NDVI}

Figure 2 (a-p) show the interannual variability (anomaly from the mean NDVI) of NDVI over the test sites in Western
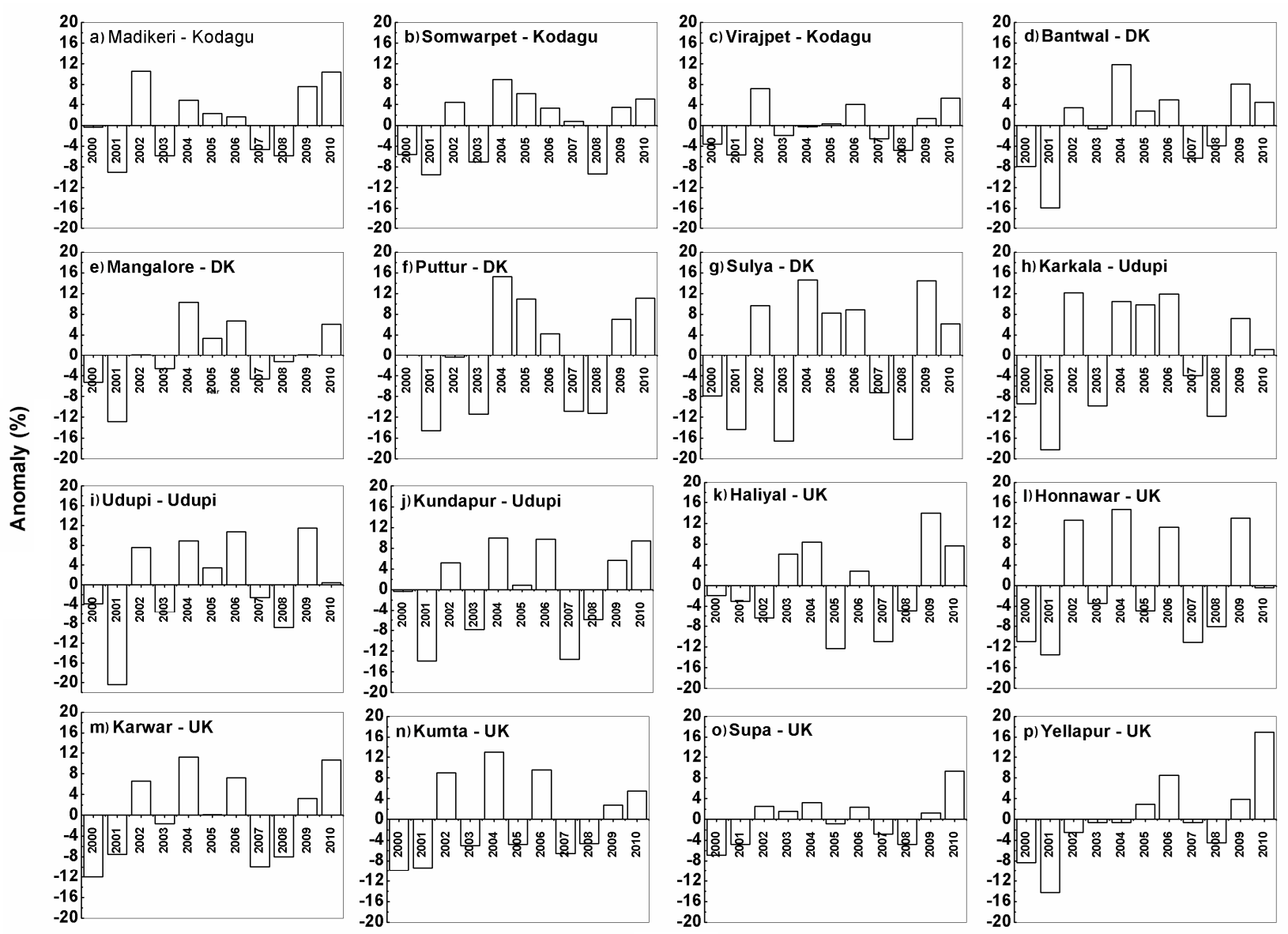

Year

Figure 2. Interannual variability of NDVI at different test sites in Western Ghats. 

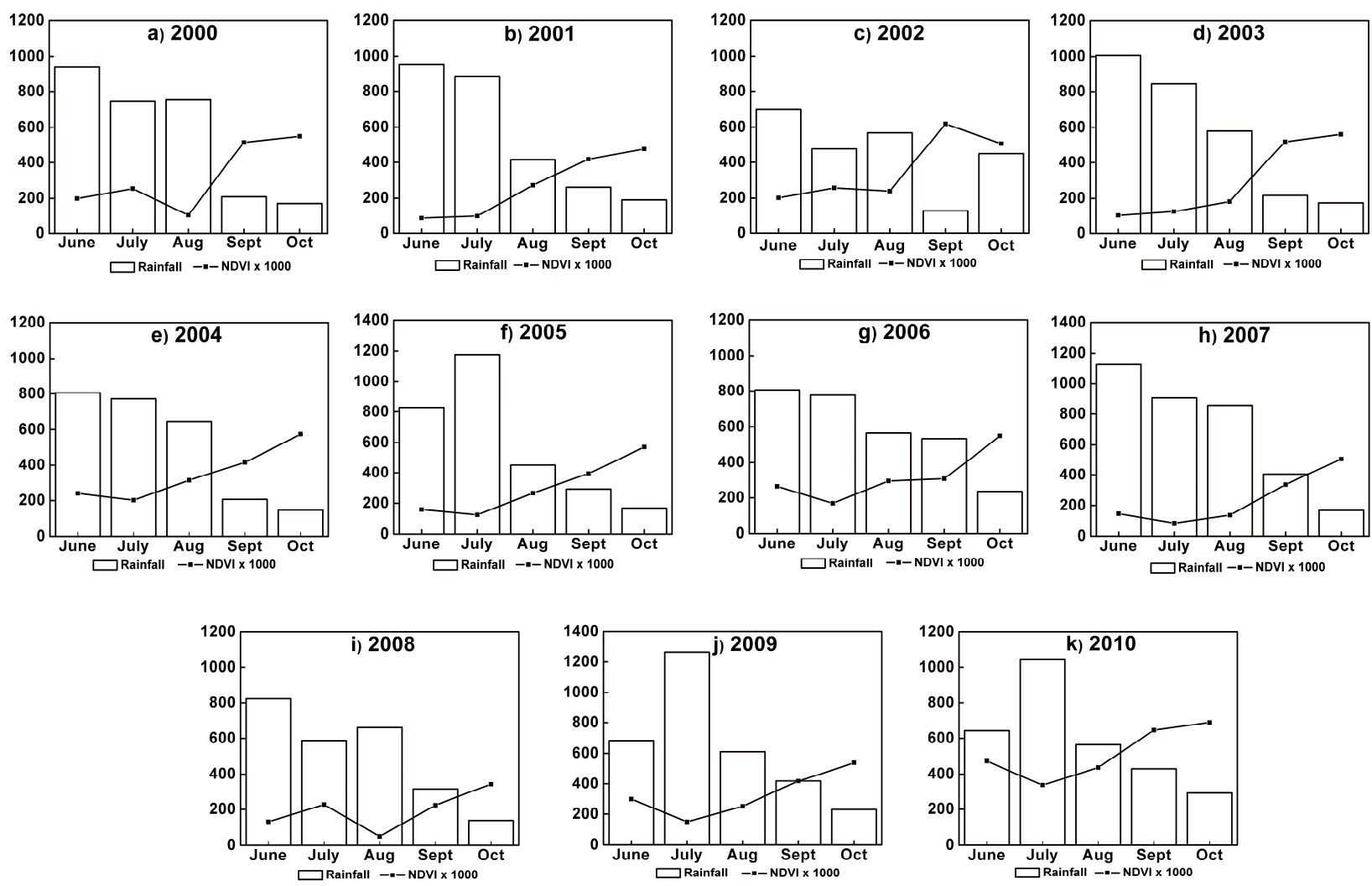

Figure 4. Monthly NDVI vs rainfall over Western Ghats for the period 2000 to 2010 from June to October.

Ghats from 2000 to 2010. The NDVI over all the test sites varied distinctly from year to year and maximum NDVI is observed in Yellapur during the year 2010 of about $17 \%$ to the normal and minimum was in the place Udupi with $-20 \%$ of normal. From Figure 2, it can be observed that the years 2000, 2001 and 2008 showed negative anomalies during all years of study period of which 2001 has undergone large variations. These changes have been attributed to the rainfall anomalies. The spatial average of all these stations which we have taken as the representative of Western Ghats as whole also showed an increasing tendency (Figure 3.). Highest anomaly of $+10 \%$ was seen in the year 2004 and a least of $-11 \%$ in 2001 . The standard deviation of 0.04 in NDVI shows the interannual variability over the study period. The increasing tendency of NDVI is an indication of improved crop production. The studies of Kumar et al. (2011) on the crops productivity of which for rice is $2387 \mathrm{~kg} / \mathrm{ha}$ and maize is $2046 \mathrm{~kg} / \mathrm{ha}$ in Western Ghats and found that rain fed rice projection will be from $-35 \%$ to $35 \%$ where as irrigated rice also will be benefited because of the $\mathrm{CO}_{2}$ fertilization effects. The limitation of this study is that the authors have not considered the irrigation effects on crops over Western Ghats. The important rain-fed crops in Western Ghats are rice, sugarcane, turmeric and onion, where as the dry crops are jowar, ragi, cotton etc. So, the rainfed crops mainly need irrigation when there is rainfall deficiency (Lele et al., 2008). Lee et al. (2008) reported that
NDVI has shown increment over Western Ghats due to irrigation in the month of July whenever there is deficiency in rainfall during 1982 to 2003.

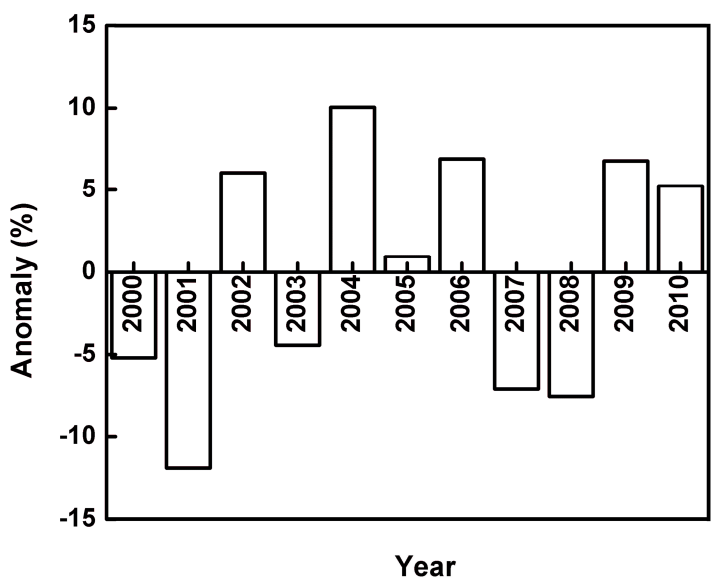

Figure 3. Interannual variability of NDVI over Western Ghats.

Figure 4(a) to 4(k) depict the monthly NDVI over Western Ghats along with a monthly rainfall for the month of June to October from 2000 to 2010. The figures infer that the vegetation is high in September and October months than the rest of the months in all the years. From the visual inspection, it is 
noticed that NDVI is slowly increasing, where as the rainfall is decreasing from June to October. Though NDVI gradually attained higher values in September / October, there were some kinks in their values during the season. In July 2006, August 2008, July 2009 and 2010, the NDVI showed lesser values than in the previous months. This can be explained with the help of rainfall anomalies over the Western Ghats. The deficit rainfall activity in July 2006 i.e $23 \%$ below the normal, consecutive deficits of rainfall in July $(-42 \%)$ and August (-24\%) of 2008 and $-8 \%$ of normal in June 2009 and $-14 \%$ of normal rainfall in June could result in lower values of vegetation during the aforementioned months. From Figure 4, it is also observed that there is no good agreement between rainfall and NDVI. From the figure, it may be inferred that the vegetation over a period of a month is also dependant on the previous month's rainfall as well as on the available water content in the soil. It is worthwhile here to mention that as the region Western Ghats is an all time humid region as reported by Sarma (2006), plenty of moisture is already available in the soil which can be utilized by the vegetation for its growth. The one-to-one and lagged correlations between rainfall and NDVI resulted in poor and insignificant values which clears that there is no direct dependence of vegetation on rainfall. So, to establish rainfall and NDVI relation over the Western Ghats which is a humid region, authors of the paper attempted to see the variations of NDVI with Antecedent Precipitation Index (API). Figure 5 gives the plot of API and NDVI for each 8 days during the Khariff season (June to October) over the Western Ghats for the period from 2000 to 2010. A coherence has been observed in API and NDVI during July and August months and as October approaches API has come down depicting the diminution of SW monsoon where as NDVI attained a maximum value which is the indication of matured/harvested stage of the crop. The overall correlation of NDVI and API is +0.53 , significant at 0.05 level and the correlation for all the years is given in Table 2. A Maximum correlation of +0.89 is observed in the year 2003, and significant correlations were seen during 2002, 2005, 2006 and 2010.

Table 2. Data Sources and Types

\begin{tabular}{cl}
\hline Year & Correlation \\
\hline 2000 & $0.41^{* *}$ \\
2001 & 0.24 \\
2002 & $0.40^{* *}$ \\
2003 & $0.89^{*}$ \\
2004 & 0.25 \\
2005 & $0.54^{* *}$ \\
2006 & $0.51^{* *}$ \\
2007 & $0.52^{* *}$ \\
2008 & 0.22 \\
2009 & 0.24 \\
2010 & $0.50^{* *}$ \\
Mean & $0.53^{* *}$ \\
${ }^{*} 0.01$ level of significance. & \\
${ }^{* *} 0.05$ level of significance. &
\end{tabular}

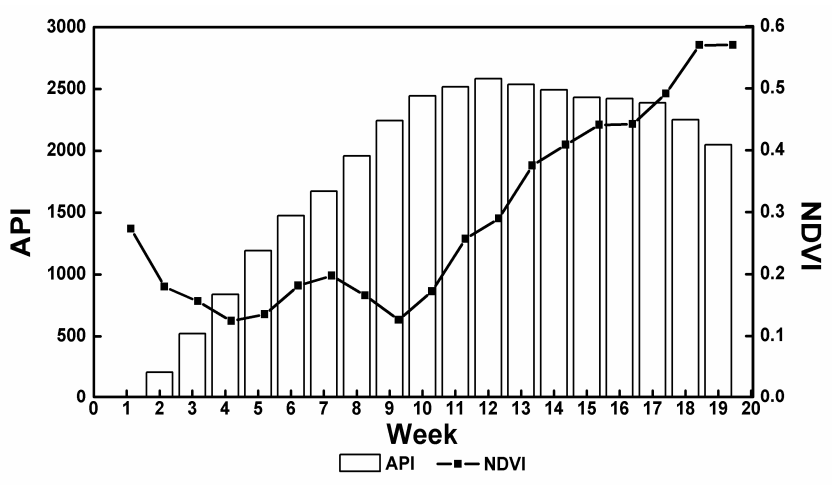

Figure 5. NDVI and API during Khariff (June to October) season.

The authors also attempted wavelet analysis to see the variations of NDVI and API. It is reported that the wavelet analysis is an efficient tool, used to analyse the localized variations of power within a time series. From the decomposition of the respective time series, one can get the information of dominant modes of variability in time-frequency space. The wavelet spectrum has been employed to several hydrologic analyses such as identification of climate impacts on stream flow (Bradshaw and Mc Intosh, 1994), flood patterns (Jiang et al., 2002) and determination of hydrologic regimes (Smith et al., 1998; Saco and Kumar, 2000). This wavelet analysis can also be applied to geophysical variables (Foufoula-Georgiou and Kumar, 1995) and the theoretical treatment of wavelet analysis is reported by Daubechies (1992). Studying NDVI variation with respect to the rainfall changes have been carried out by many people (Lark and Webster, 1999; He et al., 2012; Yang et al., 2012). He et al. (2012) used 10 day composite AVHRR NDVI data from 1985 to 2007 and examined the seasonal and inter-annual relationships with rainfall by applying the wavelet spectral analysis over Canadian Ecosystems. They delineated that the NDVI and rainfall relation is significant and NDVI maintained the $3 \sim 4$ years periodicity which is associated with rainfall. Also, it is reported that the wavelet analysis is a very useful technique in order to investigate the impact of climate factors on NDVI with most suitable time scale (Yang et al., 2012). In the present study also, we used NDVI and API which is a by-product of rainfall to understand the periodicities associated with them. Figure 6 depicts the wavelet power spectra of NDVI and API where similar variations were identified in these parameters. They both exhibited a highest power around 16 composite periodicity during the monsoon months. The domination of this mode resembles the consistent increment of NDVI in the months of August and September. This periodicity revealed the Rate of Green Up stage, one of the crop phenological stages where the NDVI and rainfall relationship is more consistent. But, these variations were not observed during the last two years of study period in NDVI where as in API, these variations were continued in almost all the years. Following this mode, other dominant mode was seen around 64 composite periodicity. The low periodicities such as 4 and 8 composites were also 
Table 3. Average NDVI, Number of Rain Events, Monsoon Distributions and Monsoon Activities over Western Ghats for SW Monsoon Season

\begin{tabular}{|c|c|c|c|c|c|c|c|c|c|c|c|c|}
\hline \multirow{2}{*}{ Year } & \multirow{2}{*}{ NDVI } & \multicolumn{3}{|c|}{ No. of Rain Events } & \multicolumn{4}{|c|}{ Monsoon Distribution (in No. of days) } & \multicolumn{4}{|c|}{ Monsoon Activity (in No. of days) } \\
\hline & & LR & MR & HR & I & $\mathrm{S}$ & FWS & WS & $\mathrm{M}_{\mathrm{W}}$ & $\mathrm{M}_{\mathrm{N}}$ & $\mathrm{M}_{\mathrm{A}}$ & $\overline{\mathrm{Mv}}$ \\
\hline 2000 & 0.319 & 17 & 40 & 26 & 23 & 15 & 18 & 66 & 49 & 45 & 7 & 21 \\
\hline 2001 & 0.270 & 20 & 42 & 24 & 23 & 7 & 18 & 74 & 49 & 55 & 3 & 14 \\
\hline 2002 & 0.348 & 20 & 40 & 16 & 26 & 10 & 27 & 59 & 66 & 40 & 4 & 11 \\
\hline 2003 & 0.287 & 21 & 46 & 22 & 17 & 12 & 17 & 76 & 42 & 64 & 4 & 12 \\
\hline 2004 & 0.341 & 18 & 41 & 22 & 26 & 9 & 22 & 65 & 47 & 62 & 1 & 12 \\
\hline 2005 & 0.289 & 17 & 44 & 26 & 20 & 13 & 16 & 73 & 39 & 63 & 5 & 15 \\
\hline 2006 & 0.311 & 16 & 46 & 25 & 23 & 13 & 12 & 74 & 46 & 59 & 3 & 13 \\
\hline 2007 & 0.235 & 18 & 42 & 34 & 10 & 11 & 25 & 76 & 27 & 68 & 11 & 15 \\
\hline 2008 & 0.193 & 19 & 39 & 22 & 21 & 22 & 21 & 58 & 63 & 39 & 7 & 13 \\
\hline 2009 & 0.330 & 20 & 40 & 26 & 16 & 15 & 29 & 62 & 53 & 46 & 4 & 19 \\
\hline 2010 & 0.356 & 22 & 48 & 26 & 9 & 13 & 19 & 81 & 44 & 55 & 10 & 12 \\
\hline
\end{tabular}

LR - Light Rain, MR - Moderate Rain, HR - Heavy Rain.

I - Isolated, S - Scattered, FWS - Fairly Wide Spread, WS - Wide Spread.

$\mathrm{M}_{\mathrm{W}}$ - Weak Monsoon, $\mathrm{M}_{\mathrm{N}}$ - Normal Monsoon, $\mathrm{M}_{\mathrm{A}}$ - Active Monsoon, $\mathrm{M}_{\mathrm{V}}$ - Vigorous Monsoon.

observed in NDVI and API. These variations were found to be more in NDVI than API. These periodicities were attributed to localized variations and also these are more observed during the preparatory stage of the crop where the relationship of rainfall and NDVI is not strong. It is also observed from Figure 6 that the variance in NDVI is more than API. In addition to main peak of power, secondary peak is observed in NDVI where as it is not seen in API during the end of the season. Gradual diminution of southwest monsoon rainfall may be the reason for not showing the peak at the end of season and optimum NDVI during the harvest season for showing the peak in NDVI.
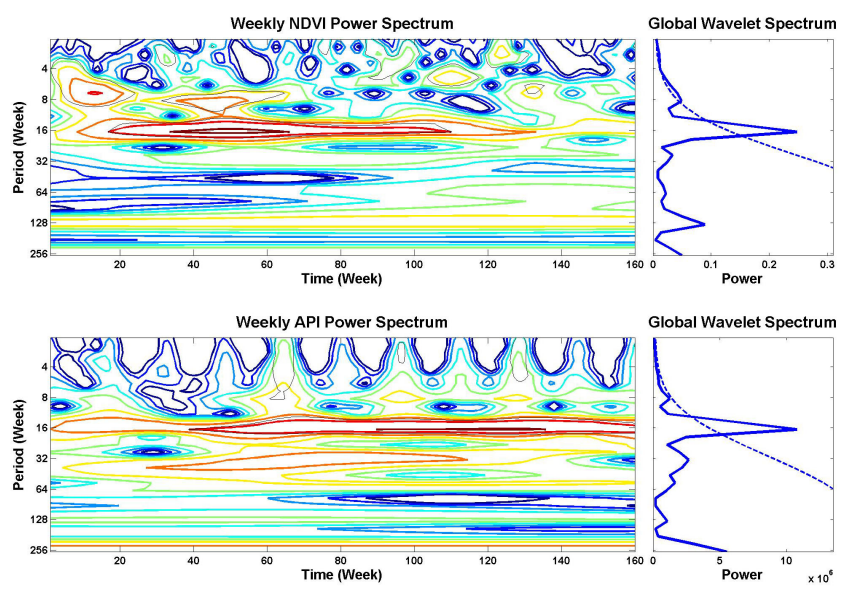

Figure 6. Wavelet spectrum of NDVI and API for the period June to October.

\subsection{NDVI vs Number of Rain Events, Monsoon Distribu- tion and Activity}

Table 3. shows the values of NDVI along with the number of rainy events, number of days of different monsoon distribution and monsoon activity for the study period over the Western Ghats. Moderate rain events played a dominant role during the monsoon in all the years of study period followed by Heavy rainy events and light rainy days. The year 2010 showed a maximum of 48 moderate rainy days and a minimum (39) in the year 2008. Similarly, highest number of heavy rainy days (34) were found in the year 2007 and the least number (16) in 2002. The average value of NDVI over the Western Ghats was found to be maximum (0.356) in 2010 and minimum in 2008 (0.193). Table 4 infers the correlation statistics of each test site with the aforementioned number of rainy days during the study period from 2000 to 2010 .

It is conspicuous from the Table 4 that all the places maintained the negative correlation with number of heavy rainy events. Two stations namely Somvarpet and Yellapur recorded positive and significant correlation with NDVI. The reason for this could be the site specific conditions such as mean elevation and the type of crop that grows in these areas. Yellapur is $561 \mathrm{~m}$ above the mean sea level which is higher compared to other stations of Uttar Kannada district where in the main crop is areca. The appropriate conditions of this crop is around $3500 \mathrm{~mm}$ of rainfall during the $\mathrm{SW}$ monsoon season which implies that this type of areas can have a positive correlation of NDVI with the heavy rainfall events. Similarly, Somvarpet is of $1080 \mathrm{~m}$ height from the mean sea level. Usually it receives the heavy rainfall because of its high altitude compared to other places in Western Ghats. Hence, the correlation of NDVI and heavy rainy days could be positive. From the correlations of light and moderate rainy days, it is to worthmention that almost all the sites maintained good correlations alternatively, i.e either with light and moderate rainy days. Only a few stations such as Virajpet, Bantwal and Yellapur could not show any considerable correlation with any of the LR and MR days. Honavar, showed the maximum correlation $(+0.70)$ with moderate rainy days among the other stations with a poor correlation of -0.33 with light rainy days. This correlation analysis shows that the vegetation at these places depend on different rain requirements based on the crop specifications (more than 12 different crops as reported by Kumar et al. (2011)). 
Table 4. Correlation of NDVI with Number of Light, Moderate and Heavy Rainy Days

\begin{tabular}{llll}
\hline \multirow{2}{*}{ Test Site } & \multicolumn{3}{c}{ Correlation } \\
\cline { 2 - 4 } Madikeri & LR & MR & HR \\
Somwarpet & -0.10 & 0.11 & -0.36 \\
Virajpet & 0.07 & 0.41 & 0.30 \\
Bantwal & 0.07 & 0.05 & -0.41 \\
Mangalore & -0.06 & -0.04 & -0.25 \\
Puttur & 0.38 & -0.03 & -0.02 \\
Sulya & -0.35 & 0.10 & -0.24 \\
Karkala & -0.50 & 0.45 & -0.62 \\
Kundhapur & -0.14 & -0.03 & 0.08 \\
Udipi & 0.55 & 0.28 & -0.57 \\
Haliyal & -0.14 & 0.13 & -0.34 \\
Honnavar & 0.70 & 0.14 & -0.39 \\
Karwar & -0.30 & 0.03 & -0.60 \\
Kumta & -0.33 & 0.56 & -0.18 \\
Supa & 0.30 & 0.56 & -0.63 \\
Yellapur & -0.02 & 0.06 & 0.09 \\
\hline
\end{tabular}

The linear variability of NDVI with a number of isolated, scattered, fairly wide spread and wide spread days is depicted in the Table 5. All the years of the study period were dominated by the number of wide spread days and is followed by isolated, fairly wide spread and scattered days. A maximum of 81 days of wide spread have been seen in the year 2011 with a minimum of 58 in the year 2008. Table.5 also depicts the number of weak, normal, active and vigorous monsoonish days over the Western Ghats from 2000 to 2010. The region is dominated by weak and normal phase of monsoon during south west monsoon as compared to the active and vigorous phases. It is interesting to note that the vigorous monsoon days were dominated by the active ones which is an indication of high intensity rains over the Western Ghats as reported by Krishnamurthy (2011). The correlation table infers the relation of NDVI with the above mentioned days. All the years have shown significant correlations with isolated and scattered distributions. All the stations maintained negative correlation with weak, normal and vigorous monsoonish days.

In addition to above, we also have seen the relation of monsoon distribution and its activity with the NDVI over the two crop phenological stages, crop preparatory period and rate of green up period respectively. We could not find any significant relation during the preparatory period but significant correlations were obtained during the rate of green up period. The correlation of NDVI during the rate of green up with isolated and scattered showed positive $(+0.52)$ and negative $(-0.27)$ with the fairly wide spread and wide spread monsoon. Similarly, positive correlations were obtained when the normal monsoon prevails. This analysis shows that the vegetation during rate of green up do not require much rainfall over Western Ghats. The multiple regression analysis disclosed the dependence of isolated, scattered rains on NDVI during the rate of green up with a variance of +0.63 . The variance in the case of weak and normal monsoon is found to be +0.61 .

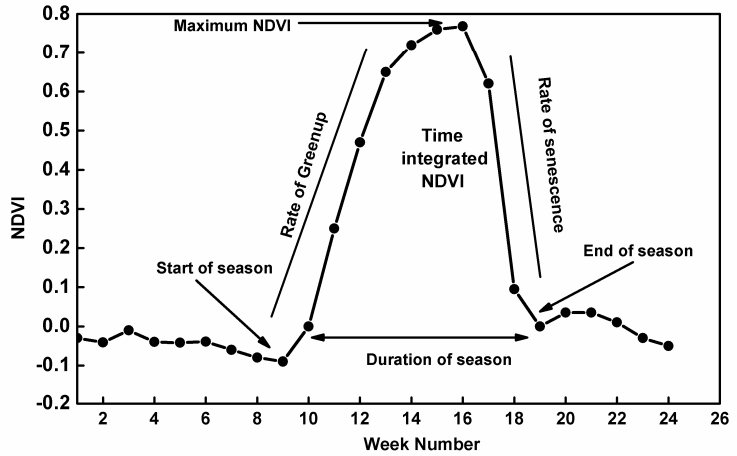

Figure 7. Different crop phenological stages.

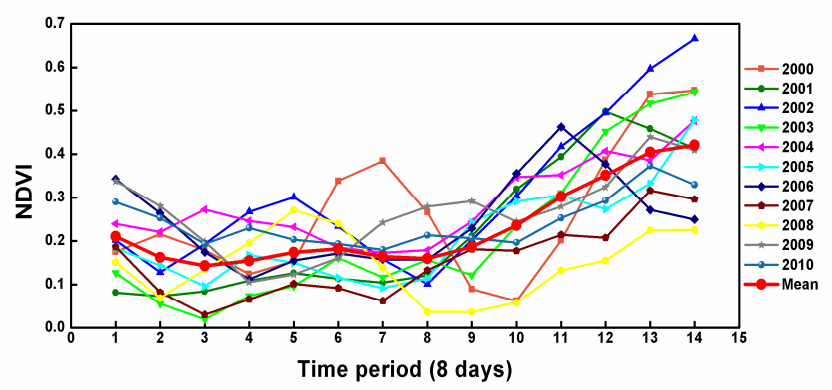

Figure 8. Three-point moving average of NDVI - Crop phenological stages over Western Ghats.

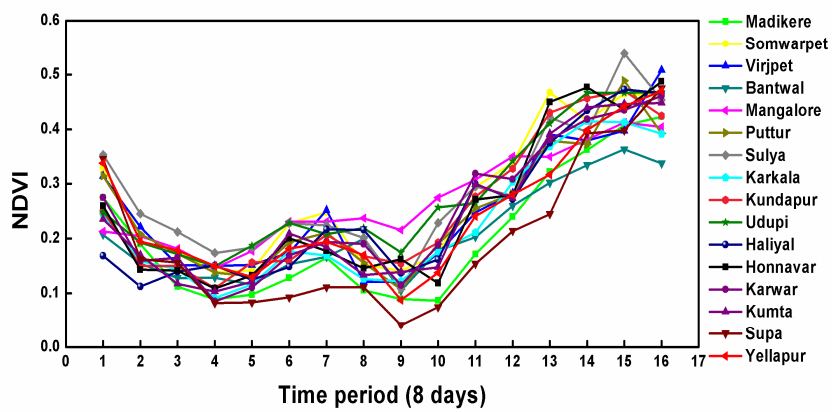

Figure 9. Crop phenological stages of different test sites in Western Ghats.

\subsection{Crop phenological stages}

Figures 7 and 8 show the general figures for depicting the different crop phenological stages over a year and the 3-point moving average of 8-day NDVI for all the years over the Western Ghats. This running average reveals that NDVI initially is low and gradually attained the optimum value during the month of October which is the month of harvesting of crops of Khariff season in the Western Ghats. Low NDVI values during the initial periods represent the crop preparatory period and starting of season. Consistent increment has been observed during the first fortnight of August in almost all the years. The rate of green up is very low in the year 2008 and is very high in the year 2002. The mean values of crop phenological stages represented in the figure show how crops have reached the matured stage from their preparatory period. The 
crop phenology at the individual test sites (Figure 9) showed distinct features in obtaining the maximum NDVI, rate of growth and start of the growing season. Almost all the stations initially i.e in the month of June maintained higher values of NDVI which decreased to some extent, as they approached the second half of July month. From hereafter, NDVI again went down to a minimum value. The minimum value of NDVI is recorded during the first half of August month. The test sites Madikeri, Supa and Yellapur exhibited a steep increase during the rate of growth period, where as the other sites showed a few fluctuations during the growing season. Comparatively, Virajpet, Sulya and Honavar showed the highest vegetation of above 0.5 during the optimum stage of the crop.

\section{Conclusions}

The paper mainly focused on establishing the relation between NDVI and rainfall over the Western Ghats. Since Western Ghats is all-time humid region, extracting relation among the above is a crucial task. It is obvious that the vegetation cannot show immediate response to rainfall when plenty of moisture is already available in the soil which can be utilized by the vegetation for its sustenance. In this case, the amount of rainfall for that particular period will have significance in addition to the antecedent rainfall. Here, in this study, we made some attempt to see the relation between NDVI and API at sixteen test sites in Western Ghats which has come out with good agreement evidenced by the strong positive correlations. A hypothesis is followed that vegetation shows fluctuations among the seasons depending upon the number of rainy days with different rain amounts. In continuation of this, we tried to emphasize the variation of NDVI with different categories of rain i.e during light rainy, moderate and heavy rainy days, and also during the different distributions and strengths of the monsoon as mentioned in the earlier sections. The study brought the interesting results such as NDVI maintained good relation either with light or moderate rainy days at different test sites. The crop phenology over the Western Ghats during June to October which is the similar period the crop season Khariff captured some of the phenological stages such as the rate of growth and optimum NDVI and the start of the season. The Rate of green up stage over Western Ghats showed that this stage do not require more water as it is evidenced by our analysis where isolated, scattered rains and normal monsoon has good relation with NDVI. The overall study is to give a deeper insight on the relations between vegetation and the amount of rainfall, number of rainy days, number of days of different monsoon distribution and the different phases of monsoon over a humid climatic region.

Acknowledgements. The corresponding author of the paper is thankful to Department of Science and Technology (DST), Govt of India for sponsoring this work under Fast Track Young Scientist Scheme.

\section{References}

Barbosa, H., and Lakshmi Kumar, T.V. (2011). Strengthening regional capacities for providing remote sensing decision support in dry lands in the context of climate variability and change, in S.S. Young and S.E. Silvern (Eds.), International Perspective of Global Environmental Change, Tech Publishers. http://dx.doi.org/10.5772/ 26323

Bradshaw, G.A., and Mc Intosh, B.A. (1994). Detecting climatic induced patterns using wavelet analysis. Environ. Pollut., 83, 135-142. http://dx.doi.org/10.1016/0269-7491(94)90031-0

Chang, T.C., Lin, T.C., Wang, S.F., and Vadeboncoeur, M.A. (2001). Assessing growing season beginning and end dates and their relation to climate in Taiwan using Satellite data. Int. J. Remote Sens., 32(18), 5035-5058. http://dx.doi.org/10.1080/01431161.2010.49 4635

Cihlar, J., St. Laurent, L., and Dyer, J.A. (1991).The relation between normalized difference vegetation index and ecological variables. Remote Sens. Environ., 35, 279-298. http://dx.doi.org/10.1016/ 0034-4257(91)90018-2

Daubechies, I. (1992). Ten Lectures on Wavelets, SIAM, Philadelphia, PA, pp. 357.

Davenport, M.L., and Nicholson, S.E. (1993). On the relation between rainfall and the Normalized Difference Vegetation Index for diverse vegetation types in East Africa. Remote Sens. Environ., 14, 2369. http://dx.doi.org/10.1080/01431169308954042

Foufoula-Georgiou, E., and Kumar, P. (Eds.) (1995). Wavelets in Geophysics, Academic Press, pp. 373.

Funk, C., and Budde, E.M. (2009). Phenologically-tuned MODIS NDVI based production anomaly estimates for Zimbabwe. Remote Sens. Environ., 113, 115-125. http://dx.doi.org/10.1016/j.rse.2008. 08.015

Gu, Y.X., Brown, J.F., Verdin, J.P., and Wardlow, B. (2007). A five year analysis of MODIS NDVI \& NDWI for grass land drought assessment over the central Great Plains of the United States. Geophys. Res. Lett., 34, L06407. http://dx.doi.org/10.1029/2006 GL029127

He, Y., Guo, X., Dixon, P., and Wilmshurt, F.J. (2012). NDVI variation and its relation to climate in Canadian Ecosystems, Canadian Geographer, 56, 492-507. http://dx.doi.org/10.1111/j.1541-0064. 2012.00441.x

Holben, B.N. (1986). Characteristics of maximum value composite images from temporal AVHRR data. Int. J. Remote Sens., 7, 1417-1434. http://dx.doi.org/10.1080/01431168608948945

Jiang, J.M., Mendelssohn, R., Schwing, F., and Fraedrich, K. (2002). Coherency detection of multiscale abrupt changes in historic Nile flood levels. Geophys. Res. Lett., 29, art no.1271, http://dx.doi.org/ 10.1029/2002GL014826

King, M.D., Closs, J., Spangler, S., and Greenstone, R. (Eds.) (2003). EOS Data Products Handbook Version I, NASA Goddard Space Flight Centre, Greenbelt, Maryland.

Knight, J.K., Lunneta, R.L., Ediriwickerma, J., and Khorram, S. (2006). Regional scale land cover characterization using MODISNDVI. $250 \mathrm{~m}$ multi- temporal imagery: A phenology based approach. GISci. Remote Sens., 43(1), 1-23. http://dx.doi.org/ 10.2747/1548-1603.43.1.1

Kogan, F. (1997). Global drought watch from space. Bull. Am. Meteorol. Soc., 78, 621-36. http://dx.doi.org/10.1175/1520-0477(1997) $078<0621$ :GDWFS $>2.0$. CO; 2

Krishnamurthy, V. (2011). Extreme Events and Trends in the Indian Summer Monsoon, COLA Technical Report, USA.

Kumar, S.N., Aggarwal, P.K., Rani, S., Jain, S., Rani, S., and Chauhan, N. (2011). Impact of climate change on crop productivity in Western Ghats, coastal and north eastern regions of India. Curr. Sci., 101(3) 332-341. 
Lakshmi Kumar, T.V., Barbosa, H., Koteswara Rao, K., and Prabha Jothi, E. (2012). Some studies on the frequency of extreme weather events over India. J. Agric. Sci. Technol., 14 (6), 1343-1356.

Lakshmi Kumar, T.V., Koteswara Rao, K., Barbosa, H., and Prabha Jothi, E. (2013). Studies on spatial pattern of NDVI and its relation to rainfall, air temperature, soil moisture adequacy and ENSO over India. Geofizika, 30, 1-18.

Lark, R.M., and Webster, R. (1999). Analysis and elucidation of soil variation using wavelets. Eur. J. Soil Sci., 50, 185-206. http:// dx.doi.org/10.1046/j.1365-2389.1999.t01-1-00234.x

Lee, E., Chase, N.T., Rajagopalan, B., Barry, G.R., Biggs, W.T., and Lawrence J.P. (2008). Effects of irrigation and vegetation activity on early Indian summer monsoon variability. Int. J. Climatol., http://dx.doi.org/10.1002/joc.1721

Lele, S., Patil, I., Badiger, S., Menon, A., and Kumar, R. (2008). (Scientific Report) The Economic Impact of Forest Hydrological Services on Local Communities: A Case Study from the Western Ghats of India, Nov. 2008.

Mallat, S. (1999). A Wavelet Tour of Signal Processing, Academic Press, 1999

Nagendra, H., and Utkarsh, G. (2003). Landscape ecological planning through a multi-scale characterization of pattern: Studies in the Western Ghats, South India. Environ. Monit. Assess., 87, 215-233. http://dx.doi.org/10.1023/A:1024878925038

Narasimhan, R., and Stow, D. (2010). Daily MODIS products for analyzing early season vegetation dynamics across the north slope of Alaska. Remote Sens. Environ., 114, 1251-1262. http://dx.doi. org/10.1016/j.rse.2010.01.017

Prasad, V.K., Badarinath, K.V.S., and Eaturu, A. (2008). Effects of precipitation, temperature and topographic parameters on evergreen vegetation greenery in the Western Ghats, India. Int. J. Climatol., http://dx.doi.org/10.1002/joc.1662
Ramesh, P.S., Sudipa, R., and Kogan, F. (2003). Vegetation and temperature condition indices from NOAA AVHRR data for drought monitoring over India. Int. J. Remote Sens., 24, 4393-4402. http:// dx.doi.org/10.1080/0143116031000084323

Rosenthal, W.D., Harlan, J.C., and Blanchard, B.J. (1982). Dryland Pasture and Crop Conditions as Seen by HCMM, Progress Report 3712-4, Remote Sensing Center, Texas A \& M University.

Saco, P., and Kumar, P. (2000). Coherent modes in multiscale variability of stream flow over Unite States. Water Resour. Res., 36, 1049-1067. http://dx.doi.org/10.1029/1999WR900345

Sarma, A.A.L.N. (2006). Modeling of water budget elements - Extreme events. Indian J. Radio Space Phys., 35, 26-34.

Schnur, M.T., Xie, H.J., and Wang, X.W. (2010). Estimating root zone soil moisture at distant sites using MODIS NDVI and EVI in a semi-arid region of southwestern USA. Ecol. Inf., 5, 400-409. http://dx.doi.org/10.1016/j.ecoinf.2010.05.001

Smith, L.C., Turcotte, D.L., and Issacks, B.L. (1998). Stream flow characterization and feature detection using a discrete wavelet transform. Hydrol. Process., 12, 233-249. http://dx.doi.org/10. 1002/(SICI)1099-1085(199802)12:2<233::AID-HYP573>3.0.CO; 2-3

Unganai, L.S., and Kogan, F.N. (1998). Southern Africa's recent droughts from space. Adv. Space Res., 21(3), 507-511. http:// dx.doi.org/10.1016/S0273-1177(97)00888-0

Wan, Z., Wang, P., and Li, X. (2004). Using MODIS land surface temperature and normalized difference vegetation index products for monitoring drought in the sourthern Great Plains, USA. Int. J. Remote Sens., 25(1), 61-72. http://dx.doi.org/10.1080/01431160 31000115328

Yang, Y., Xu, J., Hong, Y., and Lv, G. (2012). The dynamics of vegetation coverage and its response to climate factors in Inner Mongolia, China. Stochastic Environ. Res. Risk Assess., 26, 357-373. $\mathrm{http} / / / \mathrm{dx}$. doi.org/10.1007/s00477-011-0481-9 